\title{
A prospective study of the relation of patient-reported outcome measures with lumbar disc surgery for herniated lumbar disc
}

\author{
Hitendra Sacriya Naik $M C h^{1}{ }^{(D)}$, Samarendra Nath Ghosh $M C h^{2}$ iD, Pradeep Kumar Saha $M D^{3}$ (D), Parthasarathy \\ Biswas $M D^{4}$ iD \\ ${ }^{1,2}$ Department of Neurosurgery, Bangur Institute of Neurosciences, IPGME\&R, Kolkata, West Bengal, India \\ ${ }^{3}$ Department of Psychiatry, Institute of Postgraduate Medical Education and Research (IPGME\&R), Kolkata, West Bengal, \\ India \\ ${ }^{4}$ Department of Psychiatry, North Bengal Medical College \& Hospital, Sushruta Nagar, Darjeeling, West Bengal, India
}

Date of submission: $8^{\text {th }}$ April 2021

Date of acceptance: $16^{\text {th }}$ August 2021

Date of publication: $1^{\text {st }}$ September 2021

\begin{abstract}
Introduction: The aim of this 6-month prospective study was to seek out the factors affecting surgical outcome, predictors of treatment response and their correlates in open discectomy for herniated lumbar disc.

Methods and Materials: Eighty patients who fulfilled the required criteria were chosen. Socio-demographic, clinical data proforma, Visual Analogue Scale for pain (VAS), Japanese Orthopedic Association (JOA) Scale for subjective and objective pain related QoL, General Health Questionnaire-12 (GHQ-12) for screening mental health, Short Form-36 (SF-36) Health Survey for assessing Health-related Quality of Life (HRQOL) and Montgomery Asberg Depression Rating Scale (MADRS) for measurement of clinical depression were used at the preoperative stage and reassessed again at 1 month, 3 months and 6 months post-discectomy.

Results: Postoperatively, VAS and JOA Scale scores continued to show improvement at each follow up ( $<<0.001)$. Majority of the SF-36 subscales showed significant improvement at 3-months and 6-months of the postoperative period. A significant correlation was seen between the duration of pain symptoms and depression scores at 6 months (rho $0.301 \mathrm{p}<0.01$ ). Baseline VAS score had a significant negative correlation with baseline Physical Functioning and General Health scores at 6 months. The duration and severity of pain symptoms before surgery predicted the depression scores at 6 months (adjusted $\mathrm{R}$ square $0.056 \mathrm{p}<0.001$ ) postoperatively.

Conclusion: The discectomy procedure resulted in significant improvement in baseline subjective pain symptoms and overall HRQOL. Greater the duration and intensity of pain symptoms at baseline, greater was the depression scores and lesser was the SF-36 physical functioning and general health at 6-month postoperative period.
\end{abstract}

Key words: Depressive symptoms, Herniated lumbar disc, Montgomery Asberg Depression Rating Scale, Short Form-36, Quality of life, Visual Analog Scale.

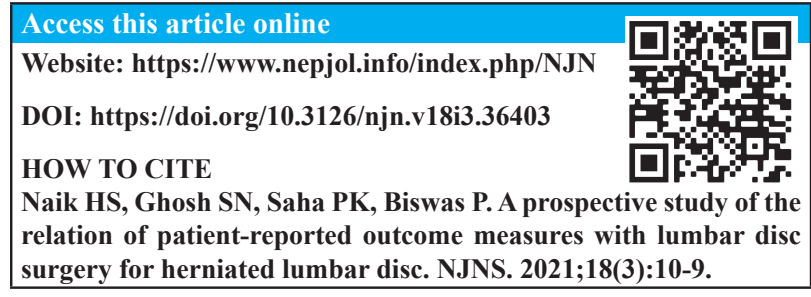

Address for correspondence:

Dr. Parthasarathy Biswas

Associate Professor, Department of Psychiatry,

North Bengal Medical College \& Hospital,

Sushruta Nagar, Darjeeling, West Bengal, India.

E-mail: ps.bs69@gmail.com

Phone: +919836778063

Copyright (C) 2021 Nepalese Society of Neurosurgeons (NESON)

ISSN: 1813-1948 (Print), 1813-1956 (Online)

This work is licensed under a Creative Commons Attribution-Non Commercial 4.0 International License.

\section{Introduction} ow back pain (LBP) is one of the most common health
problems worldwide and a major cause of disability
that affects performance at work and general well-being. ${ }^{1-4}$
LBP has an incidence of $15 \%$ amongst adults and a point
prevalence of $30 \% .^{5,6}$ It is the leading cause of limitation in
activity and absenteeism from work. ${ }^{5-8}$
Disc herniation is one of the important causes of LBP
with L $4 / 5$ and L5/ S1 being the most common levels.
9,10 Herniated lumbar disc is defined as the displacement
of disc material (nucleus pulposus or annulus fibrosus)
beyond the intervertebral disc space. ${ }^{11}$ The highest
prevalence of disc herniation is seen in those aged 30 to50
years and has a male preponderance. In people belonging
to the younger age group (25-55 years), about $95 \%$ of
prolapsed intervertebral disc (PIVD) occurs at the lower
lumbar spine (L4/5 and L5/S1 level) whereas PIVD above 
this level is more common in older age group. ${ }^{12}$ Treatment with medications like analgesics/ muscle relaxants or epidural injections of corticosteroids have not been found to be gratifying. ${ }^{11,13}$ About $10 \%$ of people have sufficient pain after 6 weeks of conservative treatment for surgery to become inevitable. ${ }^{13}$ Therefore open discectomy or microdiscectomy is recommended when conservative treatment fails and $70 \%$ to $90 \%$ respond to these surgical interventions. ${ }^{14}$ Moderate to severe clinical evidence of nerve root compression that has residual or unremitting radicular symptoms after poor response to the oral analgesics and other forms of conservative treatment modalities have been considered as the indications for surgery. ${ }^{15}$

Open Discectomy and microdiscectomy for single level disc herniation have been shown to give the maximum gratifying outcomes post surgery when assessed on EQ-5D. ${ }^{16}$ Health-related quality of life (HRQoL) is a multidimensional concept that includes domains related to physical, mental emotional and social functioning that may be affected by a disorder and its interventions. EuroQol-5 Dimension (EQ-5D) $)^{17,18}$ and the 36-item ShortForm Health Survey (SF-36) are the most commonly used HRQoL scales. ${ }^{19,20}$ Patient's satisfaction with treatment, ${ }^{21}$ and HRQoL have increasingly been used in spinal surgery research of late..$^{22-24}$

Visual analogue scale (VAS) score is one of the most common scales used to assess pain symptoms (constant leg pain, backache, and severe episodic leg pain) in patients with symptomatic lumbar disc herniation. ${ }^{25}$ VASLeg Pain-Severe was found to be the most responsive VAS measure when evaluating the results of discectomy surgery for sciatica. ${ }^{25}$ The 15-point Japanese Orthopedic Association (JOA) low back pain score is widely used in assessment of sciatica patients which has both subjective and clinician rated (objective) sub scales. ${ }^{26}$

Psychosocial factors and their influence on the outcome of disc surgeries have been the focus of recent research from developed countries. Depression and anxiety scores of spinal surgery patients have been shown to improve in postoperative period. ${ }^{27}$

However when improvements in the 12-month patient related outcomes were compared between patients with persistent or postoperatively developed depression/ anxiety and those with no depression or anxiety symptoms before or after surgery it was found that improvement in the former group was smaller as compared to the latter groups. ${ }^{28}$ Predictors of poor response to surgical treatment was found to be preoperative high scores on depression, anxiety, somatization and poor coping in a systematic review..$^{29}$ Depressive symptoms in the preoperative and early recovery phase were found to be strong predictors of a poorer outcome. ${ }^{30}$ Depressive symptoms in the preoperative and early recovery phase were found to be strong predictors of a poorer self-reported surgery outcome on 1-year follow-up. ${ }^{30} \mathrm{~A}$ systematic review of fourteen studies found the prevalence rates for depression and anxiety varied between $21.5 \%$ and $49.3 \%$ before and between $4.1 \%$ and $79.6 \%$ after disc surgery. ${ }^{31}$ It was concluded that depression and anxiety were found to have a great impact on the postoperative outcome of surgery. ${ }^{30}$

Little research has been done from the Indian subcontinent to prospectively investigate depression and anxiety in patients undergoing surgery for single level herniated discs. Most of the researches on VAS and Health-related QoL were retrospective chart reviews. ${ }^{32,33}$

\section{Methods and Materials}

In the present 6-month prospective study, patients who were admitted for elective discectomy for single level lumbar PIVD were selected for the study. This prospective study tries to answer some of the lacunae in literature.

The approval for this study was obtained from the institutional ethics committee of this tertiary care referral Government Institute from Eastern India. The prior informed consent was taken from subjects. Only those patients who were clinically diagnosed (positive Straight Leg Raising test) with lumbar PIVD at single level and which was reconfirmed radiologically by doing Magnetic Resonance Imaging (MRI) were included in the study. Symptomatic patients of PIVD who did not respond to conservative treatment were admitted in the Neurosurgery Ward of this institute. The exclusion criteria included patients with prior history of spinal surgery, history of other spinal pathologies, presence of chronic medical illnesses, history of severe mental disorders, presence of substance abuse (except nicotine) and those in whom disc herniation was not proven radiologically.

The study was done for a period of one and half years (January 2014 to May 2015) and another 6 months were spent in data tabulation and analysis. Hundred patients fulfilled the inclusion and exclusion and were originally recruited for the study by purposive sampling method. The attrition rate for various reasons was 20 percent so the final sample size was 80 .

The primary objectives of this present study were a descriptive and correlational analysis of socio demographic, clinical profile, subjective pain symptoms, subjective and health-related quality of life in these patients. The other objectives were to find out the predictors of good and poor surgical outcomes. Widely used and well validated scales such as Short Form (SF-36) Health Survey ${ }^{19,20}$ for assessing Health Related Quality of life, Visual Analog Scale (VAS) for assessing pain symptoms and Japanese Orthopedics Association (JOA) a 15-point scale ${ }^{26}$ used to assess low back pain, subjective and clinician rated objective QOL assessment in sciatica patients were used. 
The General Health Questionnaire (GHQ-12) which is a 12-item screening device for identifying common mental disorders in various settings including non-psychiatric clinical settings was used in the index study. ${ }^{34}$ Each item assesses the severity of mental problems over the past few weeks using a 4-point scale. The score ranges from 0 to 36 , with higher scores indicating worse conditions of mental problems and is well validated in Indian population. ${ }^{35}$

Montgomery-Asberg Depression Rating Scale (MADRS) was used for assessing depressive symptoms. It is a 10 -item semi-structured scale specifically designed to indicate the severity of the depressive condition and to measure change during treatment. ${ }^{36}$ The MADRS was chosen over the Hamilton Depression rating scale (HAM-D)because it is relatively quick to administer, and unlike the HAM-D, does not focus predominantly on the somatic symptoms of depression, but rather addresses core mood symptoms such as sadness, tension, lassitude, pessimistic thoughts, and suicidal thoughts. ${ }^{37}$ MADRS score of $>7$ is indicative of Major Depressive Disorder.

The Short Form 36 (SF-36) Health Survey ${ }^{19,20}$ questionnaire has eight subscales viz. physical functioning, role physical, bodily pain, general health, vitality, social functioning, role emotional and mental health. Each subscale is scored from 0 to 100 . We chose this scale because of its ability to provide us with a comprehensive quantitative measurement of HRQOL. Furthermore the VAS Scores, the JOA subjective and clinician rated objective quality of life (QOL) scores, GHQ scores and MADRS scores were assessed at four different points viz. Before Surgery (S0), 1-month post-surgery (S1), 3 months post-surgery (S2) and at 6 months post-surgery (S3) and were subsequently compared.

Statistical Package for Social Sciences (SPSS Inc released 2009), version 16.0 (Chicago, IL) was used to analyze the data. ${ }^{38}$ Appropriate parametric and nonparametric statistical analysis was done to find the frequency tables and means. One-way ANOVA was used to compare the HRQoL Scores, JOA scores, VAS scores, General Health scores and depression scores across the various follow-up time points as mentioned above. Post hoc analysis was also done to find the differences between each time point. Pearson's correlation coefficient was used to find a correlation between two continuous variables and Spearman's rho was used to find a correlation between two discrete variables. Regression Univariate analysis was used to find the predictors of the outcome of disc surgery.

\section{Results}

As mentioned in the methodology due to an attrition rate of 20 percent our ultimate patient number stood at 80 . The mean age of the sample was $37.58 \pm 8.00$ years (Range 19 to 60 years). The sample had a male preponderance
(63.8\%). Majority of patients were married, $60 \%(n=48)$ were employed and more than $80 \%$ were either educated up to primary school or up to matriculation. Three-fourth of the patients belonged to rural backgrounds and $81.2 \%$ belonged to Hindu religion. Most patients (65\%) came to our department themselves whereas $26.2 \%$ were referred to us from other departments.

The range of SLRT (Straight Leg Raising Test) was positive (between 60-80 degrees) in all patients. The most common level of disc herniation was at L4-L5 level as proven by MRI of the lumbar spine $(77.5 \%$; $n=62)$ which was followed by L5-S1. In more than half of patients $(n=42)$, Low Back Pain (LBP) with Radiculopathy was the most common presenting complaint followed by Radiculopathy $(n=28)$ and paresthesia $(n=10)$.

Table 1 illustrates that Leg Pain was assessed using VAS scale on a Likert scale of $0-10$ with 0 being no pain and 10 being the worst possible pain. In our study group, patients had highest scores before surgery which decreased significantly at all the 3 follow-ups. Table 1 also illustrates the scores of 2 subscales of the Japanese Orthopedic Association (JOA) for patients with Lumbar Disc Herniation. The 2 subscales were subjective pain and QoL (9 points) and clinician rated QoL (6 points). On the JOA scale, more the score, lesser is the severity of clinical symptoms and better is the QoL. The scores of clinical signs (objective) subscale were lower before surgery in our patients and showed a significant increase in scores at $1^{\text {st }}\left(\mathrm{S}_{1}\right), 3^{\text {rd }}\left(\mathrm{S}_{2}\right)$ and $6^{\text {th }}\left(\mathrm{S}_{3}\right)$ month follow-ups. However, the subjective QoL subscale improved significantly only at $3^{\text {rd }}$ and $6^{\text {th }}$ months.

On the GHQ-12 questionnaire, higher the score more are the chances that the patient may have a psychiatric illness. The mean GHQ scores in preoperative period $\left(\mathrm{S}_{0}\right)$ was $12.27 \pm 1.17$, at 1-month follow-up $\left(\mathrm{S}_{1}\right)$ and at 3-month follow-up $\left(\mathrm{S}_{2}\right)$ was $12.00 \pm 0.96$ and the 6-month follow- up $\left(\mathrm{S}_{3}\right)$ scores was $10.33 \pm 0.88$. On applying oneway ANOVA and Tukey's HSD Post-Hoc test it showed that GHQ scores were higher in the preoperative period which significantly became lower only at the end of 6 months $(\mathrm{p}<0.01)$.

MADRS scores have a cut of 7 points which is considered euthymic. The mean MADRS scores in the preoperative period $\left(\mathrm{S}_{0}\right)$ was $7.65 \pm 6.18$, at 1-month follow-up $\left(\mathrm{S}_{1}\right)$ was $6.92 \pm 4.74$, at 3-month follow-up $\left(\mathrm{S}_{2}\right)$ was $6.38 \pm 3.45$ and the 6-month follow- up $\left(\mathrm{S}_{3}\right)$ scores was 5.61 \pm 1.46 . On applying one-way ANOVA and Tukey's HSD Post-Hoc test it showed that MADRS mean scores were significantly lower compared to pre-surgery scores only at 6 -month follow-up $(\mathrm{p}<0.05)$.

Table 3 shows correlation of baseline factors like age, gender, presenting complaints, duration of symptoms, and level of disc herniation with the outcome variables like the subscales of SF-36 and MADRS scores at baseline 
and at 6 months. We found that age, type of presenting complaint and level of disc herniation did not have any significant correlation with any of the outcome variables. Gender had significant correlation in terms of Physical Functioning $(\mathrm{PF})$ at 6 months, General Health $(\mathrm{GH})$ at baseline, Role Emotion (RE) at baseline and Mental Health (MH) at baseline with females having higher scores on all these subscales in comparison to males. Duration of symptoms had significant negative correlation with Social Functioning (SF) at baseline suggesting that those with duration of symptoms less than 6 months had higher scores on SF at baseline. The most striking finding was the significant positive correlation between the duration of symptoms and MADRS Scores at 6 months $\left(\mathrm{S}_{3}\right)$.
Table 4 shows that Baseline VAS score had significant negative correlation with baseline PF score, GH scores at 6 months and significant positive correlation with MADRS score at 6 months. Baseline GHQ 12 scores had significant negative correlation with PF, RP, BP, $\mathrm{GH}$, Vitality, RE and $\mathrm{MH}$ subscales at baseline. It also showed significant positive correlations with MADRS scores both at baseline and at 6 months. Baseline Japanese Orthopedic Association (JOA) subjective scores have significant negative correlation with Role Physical (RP), Role Emotional (RE), Mental Health (MH) at baseline and Bodily Pain (BP) at 6 months post operation $\left(\mathrm{S}_{3}\right)$. The Baseline Japanese Orthopedic Association (JOA) clinical scores did not show any correlation with the surgical outcome parameters.

\begin{tabular}{|c|c|c|c|c|c|}
\hline Scales & $\begin{array}{c}\text { Before surgery }\left(\mathbf{S}_{0}\right) \\
\text { Mean } \pm \text { SD }\end{array}$ & $\begin{array}{l}\text { 1-month follow- } \\
\text { up }\left(\mathrm{S}_{1}\right) \\
\text { Mean } \pm \text { SD }\end{array}$ & $\begin{array}{c}\text { 3-month follow- } \\
\text { up }\left(\mathrm{S}_{2}\right) \\
\text { Mean } \pm \mathrm{SD}\end{array}$ & $\begin{array}{c}\text { 6-month } \\
\text { follow- up }\left(\mathrm{S}_{3}\right) \\
\text { Mean } \pm \text { SD }\end{array}$ & $\begin{array}{c}\text { P value } \\
\text { (Tukey HSD test) }\end{array}$ \\
\hline VAS Scores & $7.00 \pm 0.00$ & $6.76 \pm 0.48$ & $6.15 \pm 0.39$ & $3.85 \pm 0.35$ & $\begin{array}{l}\mathrm{S}_{0}>\mathrm{S}_{1}>\mathrm{S}_{2}>\mathrm{S}_{3} \\
\mathrm{p}<0.001\end{array}$ \\
\hline JOA Subjective & \pm 0.704 & $4.84 \pm 0.719$ & $6.72 \pm 0.729$ & $7.20 \pm 0.604$ & $\begin{array}{l}\mathrm{S}_{0}=\mathrm{S}_{1}<\mathrm{S}_{2}<\mathrm{S}_{3} \\
\mathrm{p}<0.001\end{array}$ \\
\hline JOA Objective & $4.15 \pm 0.359$ & $4.40 \pm 0.493$ & $4.85 \pm 0.359$ & $5.26 \pm 0.443$ & $\begin{array}{l}\mathrm{S}_{0}<\mathrm{S}_{1}<\mathrm{S}_{2}<\mathrm{S}_{3} \\
\mathrm{p}<0.001\end{array}$ \\
\hline
\end{tabular}

Table 1: Comparison of Visual Analog Scale (VAS) scores, JOA Subjective and JOA Objective using one-way ANOVA and Post-Hoc test.

\begin{tabular}{|c|c|c|c|c|c|}
\hline Subscale & $\begin{array}{l}\text { Before surgery } \\
\qquad\left(\mathrm{S}_{0}\right) \\
\text { Mean } \pm \text { SD }\end{array}$ & $\begin{array}{l}\text { 1-month follow- } \\
\text { up }\left(\mathrm{S}_{1}\right) \\
\text { Mean } \pm \mathrm{SD}\end{array}$ & $\begin{array}{l}\text { 3-month follow- } \\
\text { up }\left(\mathrm{S}_{2}\right) \\
\text { Mean } \pm \mathrm{SD}\end{array}$ & $\begin{array}{l}\text { 6-month } \\
\text { follow- up }\left(\mathrm{S}_{3}\right) \\
\text { Mean } \pm \mathrm{SD}\end{array}$ & $\begin{array}{c}\text { P value } \\
\text { (Tukey's HSD Post- } \\
\text { Hoc test) }\end{array}$ \\
\hline $\begin{array}{l}\text { Physical } \\
\text { functioning }\end{array}$ & $61.0 \pm 6.02$ & $79.4 \pm 5.4$ & $87.1 \pm 3.7$ & $91.06 \pm 5.4$ & $\begin{array}{c}\mathrm{S}_{0}<\mathrm{S}_{1}<\mathrm{S}_{2}<\mathrm{S}_{3} \\
\mathrm{p}<0.01^{* *}\end{array}$ \\
\hline Role physical & $57.5 \pm 16.1$ & $78.5 \pm 11.4$ & $78.56 \pm 11.40$ & $84.93 \pm 12.48$ & $\mathrm{~S}_{0}<\mathrm{S}_{1}<\mathrm{S}_{2}<\mathrm{S}_{3} \mathrm{p}<0.01 * *$ \\
\hline Bodily Pain & $36.01 \pm 8.35$ & $76.35 \pm 5.20$ & $89.97 \pm 13.24$ & $95.12 \pm 10.21$ & $\mathrm{~S}_{0}<\mathrm{S}_{1}<\mathrm{S}_{2}<\mathrm{S}_{3} \mathrm{p}<0.01 * *$ \\
\hline General health & $45.25 \pm 10.96$ & $68.1 \pm 11.06$ & $73.67 \pm 14.07$ & $80.43 \pm 4.87$ & $\mathrm{~S}_{0}<\mathrm{S}_{1}<\mathrm{S}_{2}<\mathrm{S}_{3} \mathrm{p}<0.01 * *$ \\
\hline Vitality & $67.34 \pm 10.45$ & $67.34 \pm 10.45$ & $71.43 \pm 11.50$ & $74.52 \pm 13.34$ & $\begin{array}{c}\mathrm{S}_{0}=\mathrm{S}_{1}=\mathrm{S}_{2}<\mathrm{S}_{3} \\
\mathrm{p}<0.01^{* *}\end{array}$ \\
\hline Social functioning & $63.28 \pm 14.38$ & $63.28 \pm 14.38$ & $63.28 \pm 14.38$ & $82.81 \pm 11.14$ & $\begin{array}{c}\mathrm{S}_{0}=\mathrm{S}_{1}=\mathrm{S}_{2}<\mathrm{S}_{3} \\
\mathrm{p}<0.01 * *\end{array}$ \\
\hline Role emotional & $67.52 \pm 23.10$ & $73.07 \pm 16.50$ & $73.07 \pm 16.50$ & $81.68 \pm 16.67$ & $\begin{array}{c}\mathrm{S}_{0}=\mathrm{S}_{1}=\mathrm{S}_{2}<\mathrm{S}_{3} \\
\mathrm{p}<0.01 * *\end{array}$ \\
\hline Mental health & $63.3 \pm 11.00$ & $75.05 \pm 7.95$ & $76 \pm 7.66$ & $80.43 \pm 10.32$ & $\mathrm{~S}_{0}<\mathrm{S}_{1}=\mathrm{S}_{2}<\mathrm{S}_{3}$ \\
\hline
\end{tabular}

NS $=$ Not Significant $* * p<0.01$.

Table 2: Comparison of HRQoL score on SF-36 using one-way ANOVA and Post-Hoc test. 


\begin{tabular}{|l|c|c|c|c|c}
\hline \multicolumn{1}{c}{$\begin{array}{c}\text { Outcome } \\
\text { variables }\end{array}$} & $\begin{array}{c}\text { Age (in years) } \\
\text { Pearson's correlation }\end{array}$ & Gender & $\begin{array}{c}\text { Presenting } \\
\text { complaints }\end{array}$ & $\begin{array}{c}\text { Duration of symptoms } \\
\text { (in months) }\end{array}$ & $\begin{array}{c}\text { Level of disc } \\
\text { Herniation }\end{array}$ \\
\hline PF-Baseline & -0.218 & 0.076 & 0.005 & 0.030 & 0.045 \\
PF- 6 month & 0.040 & $0.021^{*}$ & -0.066 & 0.106 & -0.088 \\
\hline RP-baseline & -0.074 & 0.055 & -0.094 & -0.003 & -0.040 \\
RP-6 month & -0.005 & 0.123 & -0.030 & 0.124 & -0.053 \\
\hline BP- baseline & -0.216 & 0.397 & -0.032 & 0.002 & 0.082 \\
BP-6 month & 0.0160 & 0.797 & -0.028 & -0.012 & 0.029 \\
GH-baseline & -0.157 & $0.021^{*}$ & -0.090 & 0.032 & 0.042 \\
GH-6 month & -0.038 & 0.054 & -0.098 & 0.153 & 0.112 \\
\hline Vitality- baseline & -0.197 & 0.097 & -0.033 & 0.113 & 0.089 \\
Vitality -6 month & -0.077 & 0.233 & -0.012 & 0.165 & 0.113 \\
\hline SF- baseline & 0.070 & 0.098 & 0.081 & $-0.224 *$ & 0.100 \\
SF -6 month & -0.021 & 0.260 & -0.156 & 0.202 & -0.214 \\
\hline RE- baseline & -0.014 & $0.014 *$ & -0.90 & 0.002 & 0.010 \\
RE-6 month & 0.060 & 0.172 & -0.007 & 0.114 & -0.066 \\
\hline MH- baseline & -0.085 & $0.026 *$ & -0.094 & 0.020 & 0.034 \\
MH-6 month & -0.005 & 0.333 & -0.013 & 0.127 & -0.063 \\
\hline MADRS- baseline & -0.027 & 0.373 & -0.048 & 0.135 & 0.023 \\
MADRS-6 month & 0.101 & 0.121 & -0.087 & $0.301 * *$ & -0.041 \\
\hline
\end{tabular}

*(In Spearman's rank correlation) - correlation significant at the 0.05 level (2-tailed).

** (In Spearman's rank correlation) - correlation significant at the 0.01 level (2-tailed).

PF-Physical Functioning, RP-Role Physical, BP-Bodily Pain, GH-General Health, SF-Social Functioning, RE-Role Emotional, MH-Mental Health.

Table 3: Correlational Analysis of HRQOL variables (outcome variables) with Socio demographic variables and clinical variables (using Spearman's rank correlation).

\begin{tabular}{|c|c|c|c|c|}
\hline \multirow[b]{2}{*}{ Outcome variables } & \multicolumn{4}{|c|}{$\begin{array}{c}\text { Baseline variables } \\
\text { Pearson's correlation coeficient }\end{array}$} \\
\hline & Baseline VAS score & $\begin{array}{c}\text { Baseline JOA } \\
\text { Subjective scores }\end{array}$ & $\begin{array}{c}\text { Baseline JOA } \\
\text { Objective scores }\end{array}$ & $\begin{array}{c}\text { Baseline GHQ } 12 \\
\text { scores }\end{array}$ \\
\hline $\begin{array}{l}\text { PF-Baseline } \\
\text { PF- } 6 \text { month }\end{array}$ & $\begin{array}{c}-0.255^{*} \\
0.149\end{array}$ & $\begin{array}{c}0.041 \\
-0.208\end{array}$ & $\begin{array}{c}0.020 \\
-0.146\end{array}$ & $\begin{array}{c}-0.475^{* *} \\
0.085\end{array}$ \\
\hline RP-baseline & 0.02 & $-0.272 *$ & -0.101 & $-0.410 * *$ \\
\hline RP- 6 month & 0.116 & -0.038 & -0.088 & -0.142 \\
\hline BP- baseline & -0.179 & 0.065 & 0.092 & $-0.342 * *$ \\
\hline BP-6 month & 0.206 & $-0.260 *$ & -0.067 & -0.24 \\
\hline GH-baseline & 0.074 & -0.208 & 0.059 & $-0.343 * *$ \\
\hline GH-6 month & $-0.304 * *$ & 0.111 & 0.016 & -0.199 \\
\hline Vit- baseline & -0.209 & 0.079 & -0.078 & $-0.312 * *$ \\
\hline Vit -6 month & 0.084 & 0.190 & -0.025 & -0.012 \\
\hline SF- baseline & 0.055 & 0.108 & -0.014 & 0.0181 \\
\hline SF -6 month & 0.109 & -0.023 & -0.070 & 0.083 \\
\hline RE- baseline & -0.058 & $-0.243^{*}$ & -0.015 & $-0.349 * *$ \\
\hline RE-6 month & 0.147 & -0.063 & -0.099 & 0.066 \\
\hline MH- baseline & 0.040 & $-0.225^{*}$ & -0.037 & $-0.375 * *$ \\
\hline MH-6 month & 0.201 & 0.070 & -0.018 & -0.087 \\
\hline MADRS- baseline & 0.183 & 0.178 & -0.050 & $0.709 * *$ \\
\hline MADRS-6month & $0.227^{*}$ & -0.018 & -0.064 & $0.759 * *$ \\
\hline
\end{tabular}

*(In Pearson correlation) - correlation significant at the 0.05 level (2-tailed).

** (In Pearson correlation) - correlation significant at the 0.01 level (2-tailed).

PF-Physical Functioning, RP-Role Physical, BP-Bodily Pain, GH-General Health, SF-Social Functioning, RE-Role Emotional, MH-Mental Health.

Table 4: Correlational analysis of HRQOL variables (outcome variables) with VAS scores, JOA (subjective and objective) scores and GHQ-12 baseline scores. 
PROM in lumbar disc surgery

\begin{tabular}{|c|c|c|c|c|c|c|c|}
\hline \multirow{2}{*}{ Model } & \multicolumn{2}{|c|}{$\begin{array}{l}\text { Unstandardized } \\
\text { Coefficients }\end{array}$} & \multirow{2}{*}{$\begin{array}{c}\text { Standardized } \\
\text { Coefficients } \\
\text { Beta }\end{array}$} & \multirow{2}{*}{ t value } & \multirow{2}{*}{ Sig } & \multicolumn{2}{|c|}{$\begin{array}{c}95 \% \text { Confidence } \\
\text { Interval }\end{array}$} \\
\hline & B & $\begin{array}{l}\text { Standard } \\
\text { Error }\end{array}$ & & & & $\begin{array}{l}\text { Lower } \\
\text { Bound }\end{array}$ & $\begin{array}{l}\text { Upper } \\
\text { Bound }\end{array}$ \\
\hline 1 (Constant) & 5.171 & 0.580 & & 8.916 & $.000 * * *$ & 6.521 & 16.499 \\
\hline Duration of Pain Symptoms & 0.414 & 0.494 & 0.137 & 0.838 & $.000 * * *$ & -.365 & 1.568 \\
\hline VAS scores $\left(\mathrm{S}^{0}\right)$ & -0.955 & 0.407 & -0.257 & -2.348 & $0.021 *$ & -1.765 & -0.145 \\
\hline Model Summary & \multicolumn{2}{|c|}{$\mathrm{R}$} & \multicolumn{2}{|c|}{ R square } & \multicolumn{3}{|c|}{$\mathrm{R}$ adjusted } \\
\hline 1 & \multicolumn{2}{|c|}{$0.303^{\alpha}$} & \multicolumn{2}{|c|}{0.092} & \multicolumn{3}{|c|}{0.056} \\
\hline
\end{tabular}

Dependent Variable: MADRS Total Scores 6 months after operation.

$\alpha$ Predictors (Constant): Duration of Pain symptoms, VAS $\left(S^{0}\right)$ scores.

$*_{p}<0.05 * * * p<0.001$

Table 5A: Linear Regression analysis of MADRS scores (outcome variables) with VAS scores and duration of pain symptoms.

\begin{tabular}{|c|c|c|c|c|c|c|c|}
\hline \multirow{2}{*}{ Model } & \multicolumn{2}{|c|}{$\begin{array}{l}\text { Unstandardized } \\
\text { Coefficients }\end{array}$} & \multirow{2}{*}{$\begin{array}{c}\text { Standardized } \\
\text { Coefficients } \\
\text { Beta }\end{array}$} & \multirow{2}{*}{ t value } & \multirow{2}{*}{ Sig } & \multicolumn{2}{|c|}{$\begin{array}{l}\text { 95\% Confidence } \\
\text { Interval }\end{array}$} \\
\hline & $\mathbf{B}$ & $\begin{array}{l}\text { Standard } \\
\text { Error }\end{array}$ & & & & $\begin{array}{l}\text { Lower } \\
\text { Bound }\end{array}$ & $\begin{array}{l}\text { Upper } \\
\text { Bound }\end{array}$ \\
\hline $\begin{array}{l}1 \text { (Constant) } \\
\text { VAS scores }\left(\mathrm{S}^{0}\right)\end{array}$ & $\begin{array}{c}86.196 \\
0.435\end{array}$ & $\begin{array}{c}19.483 \\
2.788\end{array}$ & 0.018 & $\begin{array}{l}4.424 \\
0.156\end{array}$ & $\begin{array}{l}0.000 * * * \\
0.000 * * *\end{array}$ & $\begin{array}{l}47.401 \\
-5.117\end{array}$ & $\begin{array}{c}124.99 \\
5.980\end{array}$ \\
\hline Model Summary & \multicolumn{2}{|c|}{$\mathrm{R}$} & \multicolumn{2}{|c|}{ R square } & \multicolumn{3}{|c|}{$\mathrm{R}$ adjusted } \\
\hline 1 & \multicolumn{2}{|c|}{$0.101^{\alpha}$} & \multicolumn{2}{|c|}{0.010} & \multicolumn{3}{|c|}{-0.153} \\
\hline
\end{tabular}

Dependent Variable: Physical Functioning and General Health subscale scores of SF-36 6 months after operation.

$\alpha$ Predictors (Constant): VAS $\left(S^{0}\right)$ scores

$* * * p<0.001$

Table 5B: Linear Regression analysis of SF-36 Physical Functioning and General Health at 6 months follow-up (outcome variables) with VAS scores.

\section{Discussion}

This study is one of the few studies where patients of single level PIVD were recruited and assessed at baseline i.e. before surgery and thereafter they were prospectively assessed at 1 month, 3 months and 6 months postoperative. This study also attempts to find the clinical correlates and predictors of surgical outcome.

The socio demographic profile of patients in our study matched previous research from Western countries, ${ }^{16,21}$, ${ }^{39,40}$ India $^{32}$ and other Asian countries. ${ }^{24,} 33$ The mean age was 37.5 years and this was similar to studies from Asian countries on PIVD at a single level. ${ }^{32,}{ }^{33}$ The strenuous labor-intensive jobs in India could have led to the male preponderance seen in our study population. Since ours is a premier referral tertiary care institute and has a vast rural catchment area hence this could explain the fact that more than $80 \%$ had a rural background. Disc herniation at L4-L5 was the most common level of herniation in almost threefourth of the patients and more than half of them $(n=42)$ presented with LBP with Radiculopathy. These findings were similar to those found by Kagaya and coworkers. ${ }^{24}$
In terms of pain symptom status, our subjects had highest scores on Visual Analogue Scale scores before surgery which decreased significantly at all the 3 followups suggesting pain relief following surgery. This is also supported by other studies of spine surgery patients that examined pain relief. ${ }^{32,}{ }^{33}$ In our study both subjective and clinician rated objective subscales of JOA showed significant improvement at all the levels of follow-up except for the $1^{\text {st }}$ month score of subjective symptoms subscale. These results are supported by other studies which also utilized JOA for assessment of pain symptoms and HRQOL. ${ }^{24}$

With exception of vitality, social functioning and role emotional subscale all the other subscales of SF-36 showed significant improvement from the $1^{\text {st }}$ month after surgery suggesting reasonably quick improvement in HRQOL after surgery. Similar findings have been seen in patients undergoing lumbar laminectomy for radiculopathy. ${ }^{39}$ Vitality, social functioning and role emotional subscales started showing improvements only after the $3^{\text {rd }}$ month and continued to improve till the end of the study period. No significant changes were observed in the MADRS mean scores till the end of the $3^{\text {rd }}$ month. However, the 
differences became statistically significant only at the $6^{\text {th }}$ month postoperative period. It could therefore be inferred that the initial lack of improvement in the three subscales of SF-36 mentioned above could be correlated to the fact that no improvement in depression scores took place till 6 months. The most affected parameters were bodily pain, physical functioning, role physical and general health. In contrast, a study by Patrick and coworkers ${ }^{41}$ found lower baseline scores on subscales of role physical, bodily pain and general health which did not improve after 3 months of follow-up.

SF-36 subscales of physical function and role physical which indicates functional status continued to progressively improve at S1, S2 and S3 (6 months postoperative). Similar improvements in functional status 6-18 months postoperatively have been reported in patients undergoing lumbar discectomy and microdiscectomy where SF-36 physical component improved from 40.6 preoperatively to 68.3 postoperatively. ${ }^{42}$ The SF-36 mental health component subscale scores improved from 48.5 to $65.1 .{ }^{42}$ In contrast Saban and his co-workers ${ }^{43}$ found that although functional status significantly improved after surgery yet subjects remained moderately disabled three months after surgery. Further research on a larger patient population would be needed to validate our findings regarding the expected time of optimal functional recovery following open discectomy or microdiscectomy.

Statistically, significant improvements were seen in eight of the nine health scores on SF-36 before and after surgery at follow-up evaluation. Only general health scores didn't improve significantly after lumbar laminectomy. ${ }^{39}$ However, we found that even the general health scores also increased significantly after surgery at follow-up evaluation. Thus, we concluded that LBP not only affects various aspects of HRQOL but also general health which was also the conclusion deduced in another study. ${ }^{24}$

The vitality subscale of SF-36 is a general measure of energy and fatigability. However, it should also be kept in mind that lack of energy and easy fatigability are also core symptoms of depression as per DSM-5 and ICD10 DCR criteria. In spite of the fact that pain symptoms on VAS Scores had improved soon after the surgical intervention, the lack of energy and fatigability measured by the Vitality subscale did not improve till the $3^{\text {rd }}$ month postoperatively. It improved only after the depression scores started improving. Therefore, pain symptoms as well as dysphoric mood secondary to pain can affect vitality. The MH subscale of SF-36 started improving from sooner after surgery and continued to improve in the second and third follow-up. Similar findings have been found in another study on patients undergoing lumbar discectomy. ${ }^{44}$ Existing research suggests that patients with lumbar pain have significant impact on day to day activities and this effect was higher in patients with lower GHQ scores. ${ }^{45}$
Literature on prevalence rates of depression/anxiety in patients undergoing discectomy is far and few. In a systematic review the prevalence rates for depression and anxiety in patients undergoing disc surgery ranged from $21.5 \%$ to $49.3 \%$ before and from $4.1 \%$ to $79.6 \%$ after disc surgery. ${ }^{31}$ Therefore it was concluded that large variation in prevalence rates of depression was mainly due to different methodologies and assessment scales used to assess patients. ${ }^{45,46}$ The prevalence of depression was $13.75 \%$ in our study patients before surgery $\left(\mathrm{S}_{0}\right)$ which decreased significantly in the subsequent months of follow ups. This relatively lower prevalence rate could be because of strict methodology employed where we exclude all patients with preexisting psychiatric comorbidities. We did not assess anxiety disorders in these patients and it could be possible that some of them may have had comorbid anxiety as well.

\section{Correlational analysis of Factors affecting the outcome of surgery}

We correlated socio demographic and clinical variables like age, gender, duration of symptoms, level of disc herniation, VAS scores before surgery and GHQ 12 score before surgery with the outcome variables like the subscales of SF-36 and MADRS scores at baseline and at 6 months. VAS scores were considered because it is the single most accurate measure of intensity of pain. The subjective symptom scale of JOA also measures pain along with QOL. Outcome studies in disc surgery for PIVD have utilized the above factors as predictors or baseline factors. ${ }^{24,44}$ Outcome variables like all subscales of SF-36 and MADRS score at baseline $\left(\mathrm{S}_{0}\right)$ and at 6 months $\left(\mathrm{S}_{3}\right)$ were considered as primary and secondary outcome variables.

We found that age, type of presenting complaint and level of disc herniation did not have significant correlation with any of the outcome variables. This finding is supported by another study where age did not have any correlation with EQ-5D values at any of the follow-ups. ${ }^{47}$ In contrast to our findings the study by Kagaya et $\mathrm{al}^{24}$ found age to be a significant predictor with age $>50$ having a better outcome. In our study duration of symptoms had significant negative correlation with Social Functioning (SF) at baseline suggesting that those with duration of symptoms less than 6 months had higher scores on SF at baseline and therefore better social functioning. This finding is similar to a previous study where lesser the duration of symptoms (less than 6 months) better was the HRQOL. ${ }^{23}$ Gender had significant correlation in terms of Physical Functioning (PF) at 6 months, General Health $(\mathrm{GH})$ at baseline, Role Emotion (RE) and Mental Health $(\mathrm{MH})$ at baseline with females having higher scores on all these subscales in comparison to males. This can be attributed to the lesser intensity of physical functions and better coping skills in females. However, in a study by Silverplats et $\mathrm{al}^{47}$ gender had no role in predicting the 
outcome. The most striking finding was the significant correlation between the duration of symptoms and MADRS Scores at 6 months $\left(\mathrm{S}_{3}\right)$ which suggests that those with longer duration of pain symptoms had higher depressive scores at 6 months post-operation $\left(\mathrm{S}_{3}\right)$.

In our study baseline intensity of pain as measured by VAS scores had significant negative correlation with baseline Physical Functioning (PF) score, General Health (GH) score at 6 months and significant positive correlation with MADRS score at 6 months suggesting thereby that at baseline worse pain was related to lesser physical functioning and general health are on expected lines. This could be due to the global and holistic improvement in general health after surgery. Higher the intensity of Bodily Pain (BP) as measured by VAS scores at baseline greater was the intensity of depression at 6 months. This could be explained by the fact that pain is one of the associated factors for occurrence of depression and both these affect each other. Similar results were found in another study ${ }^{47}$ where it was found that leg pain but not back pain at baseline correlated significantly with EQ 5D scores. In a study it was seen that patients' pre-operative QOL scores decreased significantly for every ten VAS units of leg pain. ${ }^{23}$

Baseline GHQ 12 scores had significant negative correlation with PF, RP, BP, GH, Vitality, RE and $\mathrm{MH}$ subscales at baseline, a finding seen in a previous study too. ${ }^{48}$ It also showed significant positive correlations with MADRS scores both at baseline and at 6 months. In other words, the lesser the general health at baseline poorer is the HRQOL scores. Similarly, the more the severity of depression on the MADRS scale at baseline, worse is the general health. These findings are supported by previous studies too. ${ }^{47,23}$ Baseline Japanese Orthopedic Association (JOA) subjective scores has significant negative correlation with Role Physical (RP), Role Emotional (RE), Mental Health (MH) at baseline and Bodily Pain (BP) at 6 months post operation $\left(\mathrm{S}_{3}\right)$. These findings are in line with the world literature where JOA has been used. On linear regression analysis (Table $5 \mathrm{~A}$ and $5 \mathrm{~B}$ ) when covariates like gender and other socio demographic variables were controlled we found that VAS scores before surgery and duration of pain symptoms predicted the MADRS scores at 6 months postoperatively (adjusted $\mathrm{R}$ square 0.056 $\mathrm{p}<0.001)$. VAS scores prior to discectomy also predicted Physical Functioning and General Health subscale scores of SF-36 at 6 months (Adjusted R square -0.153 p $<0.001$ ).

Although our study has methodological advantages over more than half of the previous studies which were retrospective in nature yet the prevalence of depression amongst the patients of lumbar disc herniation derived from a small sample size may not be generalizable. We acknowledge that the use of too many variables was a function of the study design approved by the institute. We also acknowledge that the presence of a healthy control group consisting of healthy relatives of patients would have helped compare prevalence rates of depression and comorbidities. A longer follow up would have been better to assess whether these variables sustain the improvements over a longer period.

\section{Conclusion}

The discectomy procedure causes significant improvement in baseline subjective pain symptoms, which led to improvements in subjective quality of life, physical functioning, social functioning, general health and overall quality of life in the postoperative period. Longer the duration of pain symptoms and higher the intensity of Bodily Pain (BP) as measured by VAS scores at baseline greater was the intensity of depression at 6 months. Initial lack of improvement in pain symptoms and functionality post-surgery could be due to depressive symptoms which took longer time to resolve. Therefore, assessment of depressive symptoms and its treatment should be a part of assessment of all patients in the preoperative as well as in the postoperative period.

\section{Conflict of Interest: None Source(s) of support: None}

\section{References}

1. Hoy D, Bain C, Williams G, March L, Brooks P, Blyth $\mathrm{F}$, et al. A systematic review of the global prevalence of low back pain. Arthritis Rheum. 2012;64(6):202837. https://doi.org/10.1002/art.34347

2. Hoy D, Brooks P, Blyth F, Buchbinder R. The epidemiology of low back pain. Best Pract Res Clin Rheumatol. 2010;24(6):769-81. https://doi. org/10.1016/j.berh.2010.10.002

3. Lee H, Hübscher M, Moseley GL, Kamper SJ, Traeger AC, Mansell G, et al. How does pain lead to disability? A systematic review and meta-analysis of mediation studies in people with back and neck pain. Pain. 2015;156(6):988-97. https://doi.org/10.1097/j. pain.0000000000000146

4. James SL, Abate D, Abate KH, Abay SM, Abbafati $\mathrm{C}$, Abbasi N, et al. Global, regional, and national incidence, prevalence, and years lived with disability for 354 diseases and injuries for 195 countries and territories, 1990-2017: A systematic analysis for the Global Burden of Disease Study 2017. Lancet. 2018;392:1789-1858. https://doi. org/10.1016/S0140-6736(18)32279-7

5. Andersson GB. Epidemiological features of chronic low-back pain. Lancet. 1999;354(9178):581-5. https://doi.org/10.1016/S0140-6736(99)01312-4 
6. Papageorgiou AC, Croft PR, Ferry S, Jayson MI, Silman AJ. Estimating the prevalence of low back pain in the general population: Evidence from the South Manchester Back Pain Survey. Spine (Phila Pa 1976). 1995;20(17):1889-94. https://doi. org/10.1097/00007632-199509000-00009

7. Driscoll T, Jacklyn G, Orchard J, Passmore E, Vos T, Freedman G, et al. The global burden of occupationally related low back pain: Estimates from the Global Burden of Disease 2010 study. Ann Rheum Dis. 2014;73(6):975-81. https://doi. org/10.1136/annrheumdis-2013-204631

8. Ferguson SA, Merryweather A, Thiese MS, Hegmann KT, Lu ML, Kapellusch JM, et al. Prevalence of low back pain, seeking medical care, and lost time due to low back pain among manual material handling workers in the United States. BMC Musculoskelet Disord. 2019;20(1):243. https://doi.org/10.1186/ s12891-019-2594-0

9. Humphreys SC, Eck JC. Clinical evaluation and treatment options for herniated lumbar disc. Am Fam Physician. 1999;59(3):575-82, 587-8. PMID: 10029785

10. Loupasis GA, Stamos K, Katonis PG, Sapkas G, Korres DS, Hartofilakidis G. Seven- to 20year outcome of lumbar discectomy. Spine (Phila Pa 1976). 1999;24(22):2313-7. https://doi. org/10.1097/00007632-199911150-00005

11. Gibson JN, Waddell G. Surgical interventions for lumbar disc prolapse. Cochrane Database Syst Rev. 2007 Jan(1): CD001350. https://doi. org/10.1002/14651858

12. Jordan J, Konstantinou K, O’Dowd J. Herniated lumbar disc. BMJ Clin Evid. 2009;2009:1118. PMID: 19445754; PMCID: PMC2907819.

13. Buttermann GR. Treatment of lumbar disc herniation: epidural steroid injection compared with discectomy. A prospective, randomized study. J Bone Joint Surg Am. 2004;86(4):670-9. PMID: 15069129.

14. Atlas SJ, Keller RB, Wu YA, Deyo RA, Singer DE. Long-term outcomes of surgical and nonsurgical management of sciatica secondary to a lumbar disc herniation: 10-year results from the maine lumbar spine study. Spine(Phila Pa 1976). 2005;30(8):927-35. https://doi.org/10.1097/01.brs.0000158954.68522.2a

15. Blamoutier A. Surgical discectomy for lumbar disc herniation: Surgical techniques. Orthop Traumatol Surg Res. 2013;99(1 Suppl):S187-96. https://doi. org/10.1016/j.otsr.2012.11.005

16. Jansson KA, Németh $G$, Granath F, Jönsson B, Blomqvist P. Health-related quality of life in patients before and after surgery for a herniated lumbar disc. J Bone Joint Surg Br. 2005;87(7):959-64. https://doi. org/10.1302/0301-620X.87B7.16240
17. EuroQol Group. EuroQol-A new facility for the measurement of health-related quality of life. Health Policy. 1990;16(3):199-208. https://doi. org/10.1016/0168-8510(90)90421-9

18. Rabin R, deCharroF.EQ-5D: a measure of health status from the EuroQol Group. Ann Med. 2001; 33(5):33743. https://doi.org/10.3109/07853890109002087

19. Ware JE Jr, Sherbourne CD. The MOS 36-item shortform health survey (SF-36). I. Conceptual framework and item selection. Med Care. 1992; 30(6):473-83. PMID: 1593914.

20. Ware JE, Kosinski M, Dewey JE. How to Score Version Two of the SF-36 ${ }^{\circledR}$ Health Survey, (Standard $\&$ Acute Forms), $2^{\text {nd }}$ Edition,: QualityMetric Incorporated; Lincoln, RI.: 2000b

21. Rönnberg K, Lind B, Zoëga B, Halldin K, Gellerstedt M, Brisby H. Patients' satisfaction with provided care/information and expectations on clinical outcome after lumbar disc herniation surgery. Spine (Phila Pa 1976). 2007;32(2):256-61. https://doi. org/10.1097/01.brs.0000251876.98496.52

22. Heider D, Kitze K, Zieger M, Riedel-Heller SG, Angermeyer MC. Health-related quality of life in patients after lumbar disc surgery: A longitudinal observational study. Qual Life Res. 2007;16(9):145360. https://doi.org/10.1007/s11136-007-9255-8

23. Jansson KA, Németh $G$, Granath F, Jönsson B, Blomqvist P. Health-related quality of life (EQ-5D) before and one year after surgery for lumbar spinal stenosis. J Bone Joint Surg Br. 2009;91(2):210-6. https://doi.org/10.1302/0301-620X.91B2.21119

24. Kagaya H, Takahashi H, Sugawara K, Kuroda T, Takahama M. Quality of life assessment before and after lumbar disc surgery. J Orthop Sci. 2005;10(5):486-9. https://doi.org/10.1007/s00776005-0920-x

25. Vishwanathan K, Braithwaite I. Comparative responsiveness of four visual analogue scales in microdiscectomy for lumbar disc herniation. Eur J Orthop Surg Traumatol. 2019;29(6):1199-1204. https://doi.org/10.1007/s00590-019-02429-Z

26. Fukui M, Chiba K, Kawakami M, Kikuchi S, Konno $\mathrm{S}$, Miyamoto M, et al. JOA Back Pain Evaluation Questionnaire: Initial report. J Orthop Sci. 2007; 12:443-50. https://doi.org/10.1007/s00776-0071162-x

27. Rahman R, Ibaseta A, Reidler JS, Andrade NS, Skolasky RL, Riley LH III, et al. Changes in patients' depression and anxiety associated with changes in patient-reported outcomes after spine surgery. J Neurosurg Spine. 2020; 32 (6): 781-88. https:// thejns.org/doi/suppl/10.3171/2019.11.SPINE19586

28. Sinikallio S, Aalto T, Airaksinen O, Herno A, Kröger H, Viinamäki $H$. Depressive burden in the 
preoperative and early recovery phase predicts poorer surgery outcome among lumbar spinal stenosis patients: A one-year prospective follow-up study. Spine (Phila Pa 1976). 2009;34(23):2573-8. https:// doi.org/10.1097/BRS.0b013e3181b317bd

29. Strom J, Bjerrum MB, Nielsen CV, Thisted CN, Nielsen TL, Laursen M, et al. Anxiety and depression in spine surgery - A systematic integrative review. The Spine J. 2018; 18(7):1-14. https://doi.org/10.1016/j. spinee.2018.03.017

30. Celestin J, Edwards RR, Jamison RN. Pretreatment psychosocial variables as predictors of outcomes following lumbar surgery and spinal cord stimulation: A systematic review and literature synthesis. Pain Med. 2009;10(4):639-53. https://doi.org/10.1111/ j.1526-4637.2009.00632.x

31. Zieger M, Schwarz R, König HH, Härter M, RiedelHeller SG. Depression and anxiety in patients undergoing herniated disc surgery: Relevant but underresearched - A systematic review. Cent Eur Neurosurg. 2010;71(1):26-34. https://doi. org/10.1055/s-0029-1225325

32. Shashank S. Comparative effectiveness of surgical and non-surgical management for patients with single level lumbar disc herniation in terms of symptom severity and quality of life. Nepal J Neurosci. 2021;18(1):28-32. https://doi.org/10.3126/ njn.v18i1.28281.

33. Koirala S, Lohani S, Bishokarma S, Koirala S, Shreshtha P. Quality of life after lumbar microscopic discectomy. Nepal J Neurosci. 2021;18(1);33-8. https://doi.org/10.3126/njn.v18i1.34941.

34. Goldberg DP, Gater R, Sartorius N, Ustun TB, Piccinelli $\mathrm{M}$, Gureje $\mathrm{O}$, et al. The validity of two versions of the GHQ in the WHO study of mental illness in general health care. Psychol Med. 1997;27(1):191-7. https://doi.org/10.1017/ s0033291796004242

35. Jacob KS, Bhugra D, Mann AH. The validation of the 12-item General Health Questionnaire among ethnic Indian women living in the United Kingdom. Psychol Med. 1997;27(5):1215-7. https://doi.org/10.1017/ s0033291796004436

36. Montgomery SA, Asberg M. A new depression scale designed to be sensitive to change. $\mathrm{Br} \mathrm{J}$ Psychiatry. 1979;134:382-9. https://doi.org/10.1192/ bjp.134.4.382

37. Stuart A, Montgomery N, Smeyatksky MR, Montgomery DB. Profiles of antidepressant activity with the Montgomery -Asberg depression rating scale. Acta Psychiat Scand. 1985;72(320):38-42. https://doi.org/10.1111/j.1600-0447.1985.tb08073.x

38. SPSS Inc. Released 2009. PASW Statistics for Windows, Version 18.0. Chicago: SPSS Inc.
39. Albert TJ, Mesa JJ, Eng K, McIntosh TC, Balderston RA. Health outcome assessment before and after lumbar laminectomy for radiculopathy. Spine (Phila Pa 1976). 1996;21(8):960-2. https://doi. org/10.1097/00007632-199604150-00010

40. Veresciagina K, Ambrozaitis KV, Spakauskas B. Health-related quality-of-life assessment in patients with low back pain using SF-36 questionnaire. Medicina (Kaunas). 2007;43(8):607-13. PMID: 17895635.

41. Patrick DL, Deyo RA, Atlas SJ, Singer DE, Chapin A, Keller RB. Assessing health-related quality of life in patients with sciatica. Spine (Phila $\mathrm{Pa}$ 1976). 1995;20(17):1899-908; https://doi. org/10.1097/00007632-199509000-00011

42. Yoon SM, Ahn SS, Kim KH, Kim YD, Cho JH, Kim DH. Comparative study of the of percutaneous endoscopic lumbar discectomy and microscopic lumbar discectomy using the tubular retractor system based on the VAS, ODI, and SF-36. Korean J Spine. 2012; 9(3):215-22. https://doi.org/10.14245/ kjs.2012.9.3.215.

43. Saban KL, Penckofer SM, Androwich I, Bryant FB. Health-related quality of life of patients following selected types of lumbar spinal surgery: A pilot study. Health Qual Life Outcomes. 2007;5:71. https://doi. org/10.1186/1477-7525-5-71

44. Farzanegan G, Alghasi M, Safari S. Quality-of-Life evaluation of patients undergoing lumbar discectomy using Short Form 36. Anesth Pain Med. 2011;1(2):736. https://doi.org/10.5812/kowsar.22287523.1998

45. Junge A, Dvorak J, Ahrens S. Predictors of bad and good outcomes of lumbar disc surgery: A prospective clinical study with recommendations for screening to avoid bad outcomes. Spine (Phila Pa 1976). 1995;20(4):460-8. https://doi. org/10.1097/00007632-199502001-00009

46. Arpino L, Iavarone A, Parlato C, Moraci A. Prognostic role of depression after lumbar disc surgery. Neurol Sci. 2004;25(3):145-7. https://doi. org/10.1007/s10072-004-0248-X

47. Silverplats K, Lind B, Zoega B, Halldin K, Gellerstedt M, Rutberg L, et al. Health-related quality of life in patients with surgically treated lumbar disc herniation: 2- and 7-year follow-up of 117 patients. Acta Orthop. 2011;82(2):198-203. https://doi.org/10. 3109/17453674.2011.566136

48. Hassanijirdehi M, Khak M, Afshari-Mirak S, Holakouie-Naieni K, Saadat S, Taheri $\mathrm{T}$ et al. Evaluation of pain and its effect on quality of life and functioning in men with spinal cord injury. Korean J Pain. 2015;28(2):129-36. https://doi.org/10.3344/ kjp.2015.28.2.129 